put on repeat prescription after only one month of treatment. Less than half had a written diagnosis of depression and over half had no clear start date recorded for treatment. Most had been seen for some reason within the previous three months and all within 9 months but there was patchy recording of information concerning the mental state. Only three of the 17 patients had a documented statement in the notes or in a hospital letter concerning the need for prolonged treatment.

Of the study group seven patients had some form of cardiac disease, two were admitted to hospital with severe constipation and one developed symptoms of prostatic obstruction. There was no mention in the notes of a need to review the antidepressant medication. The indications for the continuation and prophylactic stages of drug treatment are laid out in Paykel \& Priest's (1992) consensus statements on the recognition and management of depression in general practice. Further guidelines on continuation or cessation of treatment and recording of clinical information may be useful to those in primary care. This may also apply to professional carers who sometimes bridge the gap between patient and doctor.

Department of Health (1993) Defeat Depression. Recognition and Management of Depression in General Practice.

Gosney, M., TAllis, R. \& Edmund, E. (1991) Biochemical abnormalities in elderly persons in part II homes. Care of the Elderly. 3, 485-488.

Paykel, E. S. \& Priest, R. G. (1992) Recognition and management of depression in general practice: consensus statement. British Medical Journal, 305, 1198-1202.

A. FARMER

Lea Castle Hospital

Wolverley

Kidderminster DY10 2PP

\section{Clozapine-induced hypotension treated with moclobemide and Bovril}

SIR: The use of clozapine is complicated by a wide range of adverse effects (Alphes et al, 1991). Hypotension occurs in $25 \%$ of patients treated with clozapine (Gaerner et al, 1989) and postural hypotension in 17\% (Naber et al, 1992). In our experience, clozapine-induced hypotension is a major cause of patient morbidity which often contributes to patients' decisions to withdraw from therapy.

Moclobemide is a reversible inhibitor of monoamine oxidase-A licensed for the treatment of depressive illness. In combination with tyramine contained in Bovril, it induced a modest but useful rise in blood pressure in a patient with central autonomic failure (Karet et al, 1993). We report the successful use of moclobemide and Bovril in a patient with clozapine-induced hypotension.

A 26-year-old, $61 \mathrm{~kg}$ male was admitted to Bethlem Royal Hospital having failed to respond to conventional neuroleptic medication. On admission his standing blood pressure was 120/80 $\mathrm{mm} \mathrm{Hg}$.

All other medication was withdrawn and clozapine started at $25 \mathrm{mg}$ at night. On day 3 of therapy, the dose was increased to $50 \mathrm{mg}$ at night, rising to $75 \mathrm{mg}$ at night on day 5 . On day 7 , the dose was further increased to $100 \mathrm{mg}$ at night but the patient complained of severe dizziness and was seen by the duty doctor. Standing blood pressure was found to be $90 / 60 \mathrm{~mm} \mathrm{Hg}$ with a postural drop of greater than $20 \mathrm{~mm} \mathrm{Hg}$.

On day 9, the clozapine dose was increased to $125 \mathrm{mg}$ at night. By day 12, the patient still complained of severe dizziness and standing diastolic pressure was unrecordable. Clozapine was reduced to $50 \mathrm{mg}$ twice daily. Some improvement ensued but standing blood pressures (measured twice daily on days 9-22) remained in the range $110-80 \mathrm{~mm} \mathrm{Hg}$ systolic, $80-40 \mathrm{~mm} \mathrm{Hg}$ diastolic and the patient continued to complain of dizziness.

By day 22, no improvement in mental state had occurred but the dose of clozapine could not be increased for fear of severe hypotension. Moclobemide was started at a dose of $150 \mathrm{mg}$ three times daily. With each dose, half a measure $(6 \mathrm{~g})$ of Bovril was given. From day 22 to day 26, standing blood pressure (measured twice daily) was in the range $110-100 \mathrm{~mm} \mathrm{Hg}$ systolic, $80-60 \mathrm{~mm} \mathrm{Hg}$ diastolic. On day 26 the dose of Bovril was increased to one measure (12 g) three times daily. After this time, twice daily standing blood pressure measurements were in the range $130-110 \mathrm{~mm} \mathrm{Hg}$ systolic, 90-70 $\mathrm{mm} \mathrm{Hg}$ diastolic. The patient did not complain of any adverse effects after day 26 despite daily questioning by nursing staff.

The introduction of moclobemide/Bovril also allowed substantial increases in the dose of clozapine. By day 54, the dose had risen to $250 \mathrm{mg} /$ day $(75 \mathrm{mg}$ am, $175 \mathrm{mg} \mathrm{pm}$ ) and the patient's mental state had improved significantly.

Hypotension is a troublesome adverse effect of clozapine. The combination of moclobemide and Bovril appears to be a safe and effective method of ameliorating this common problem. The use of the combination may also decrease the number of patients discontinuing clozapine and, at the same time, allow more effective use of the drug.

Alphes, L. D., Meltzer, H. Y., Bastani, B., et al (1991) Sideeffects of clozapine and their management. Pharmacopsychiatry. $24,46$. 
Gaerner, H. J., Fischer, E. \& Hoss, J. (1989) Side-efiects of clozapine. Psychopharmacology, 99 (suppl.), S97-S100.

Karet, F. E., Dickerson, J. E. C., Brown, J., et al (1993) Bovril and moclobemide: a novel therapeutic strategy for autonomic failure. Lancet, 344, 1263-1265.

Naber, D., Holzbach, R., Perro, C., et al (1992) Clinical management of clozapine patients in relation to efficacy and side-effects. British Journal of Psychiatry, 160 (suppl. 17), 54-59.

D. TAYLOR

A. REVELEY

Maudsley Hospital

F. FaIVRE

London SE5 8 AZ

Extreme suicidality following serotonin syndrome

SIR: Dursun et al (1995) suggest that toxic serotonin syndrome (TSS) remains underreported and misdiagnosed. We wish to report extreme suicidality in a 17-year-old schoolgirl following the serotonin syndrome attributed to phenelzine, dothiepin and lithium which she had been receiving for a month for a treatment-resistant depression. During treatment, the patient developed the cardinal features of TSS: pyrexia, opisthonus, rigidity, restlessness and tremor (Sternbach, 1991) in the absence of recent treatment with neuroleptics or other aetiologies (Dursun et al, 1995). She recovered from TSS within two weeks of discontinuing all drugs and reverted back to her previous depressive stupor-requiring feeding via a nasogastric tube. She was subsequently transferred to our care and six weeks after TSS, clomipramine 25 increasing to $50 \mathrm{mg}$ was introduced. Within seven days of this, the patient developed an active suicidal drive. She made continuous efforts to lacerate herself and tried to ingest various objects, stating "I feel so awful I must die". Nursing staff had to remain hypervigilant as she would attempt to harm herself with any objects available such as light bulbs, pencils and glassware. The patient required continuous physical restraint from two nursing staff. Senior consultants with special expertise in mood disorders commented that the degree of suicidal drive, which lasted six weeks, was unprecedented in their experience. At six weeks the clomipramine was discontinued and the patient was treated with a repeat course of twelve ECT with a full recovery.

Although serotonergic drugs such as fluoxetine do not precipitate suicide (Beasley et al, 1991), it is suggested that paradoxical increases in suicidality may occur in some patients treated with drugs affecting serotonergic transmission (Mann \& Kapur, 1991). This case suggests that, following serotonin syndrome, increased sensitivity to even cautious reinstatement of a drug with serotonergic properties (clomipramine), may occur. Although the serotonin syndrome is rare, careful study of patients in the aftermath of TSS is indicated.

Beasley, C. M., DORnseif, B. E., Bosomworth, J. C., et al (1991) Fluoxetine and suicide: a meta-analysis of controlled trials in the treatment of depression. British Medical Journal, 303, 685-692.

Dursun, S. M., Burke, J. G. \& Reveley, M. A. (1995) Toxic serotonin syndrome or extrapyramidal side-effects? (Letter). British Journal of Psychiatry, 166, 401-402.

MANN, J. J. \& KAPUR, S. (1991) The emergence of suicidal ideation and behaviour during antidepressant pharmacology. Archives of General Psychiatry, 48, 1027-1033.

STERNBACH, H. (1991) The serotonin syndrome. American Journal of Psychiatry, 148, 705-713.

M. A. Serfaty

S. MCCLUSKEY

D. ECCLESTON

Royal Victoria Infirmary

Queen Victoria Road

Newcastle upon Tyne NE1 4LP

\section{Brain damage and tardive dyskinesia}

SIR: I note with interest Pourcher et al (1995) suggest "occult acquired brain damage" as an aetiological factor in the development of neuroleptic-induced tardive dyskinesia (TD). The following two cases suggest a similar risk factor for SSRI-induced extrapyramidal side effects (EPS) and TD.

Case 1: A 32-year-old man presented with a depressive illness and was treated with paroxetine $20 \mathrm{mg} /$ day. At the age of 21 he had suffered a pontine haemorrhage due to undiagnosed hypertension that resulted in a left hemiplegia. He subsequently made a full neurological recovery. Within a few days of commencing paroxetine he developed left-sided dystonia of such severity that he was unable to walk. The paroxetine was discontinued and within a week his mobility had returned to baseline. He was then treated uneventfully with dothiepin.

Case 2: A 62-year old woman with Parkinson's disease and mild dementia presented with a depressive illness and was treated with paroxetine $20 \mathrm{mg} /$ day. Her anti-parkinsonian medications were unchanged. Over a three week period her mobility declined, due to increased rigidity and bradykinesia, from walking with the aid of one person to requiring three people to mobilise her. She also developed buccolingual masticatory TD. The paroxetine was discontinued and over the course of a month she regained her mobility. The TD however remains unchanged at four months. Her depression has been treated with trazadone to some effect. 